\title{
Citrus hystrix (makrut oil) oral sprays inhibit Streptococcus mutans biofilm formation
}

\author{
Kemthong Mitrakul ${ }^{\mathrm{a}, *}$, Ratchapin Srisatjaluk ${ }^{\mathrm{b}}$, Vimol Srisukh $^{\mathrm{c}}$, Kadkao Vongsawan $^{\mathrm{a}}$ \\ ${ }^{a}$ Department of Pediatric Dentistry, Faculty of Dentistry, Mahidol University, Bangkok 10400 Thailand \\ b Department of Oral Microbiology, Faculty of Dentistry, Mahidol University, Bangkok 10400 Thailand \\ c Department of Food Chemistry, Faculty of Pharmacy, Mahidol University, Bangkok 10400 Thailand
}

*Corresponding author, e-mail: mkemthong@yahoo.com

Received 6 Jul 2015

Accepted 17 Dec 2015

\begin{abstract}
This study evaluated the susceptibility of Streptococcus mutans (ATCC 25175) and 9 clinical isolates from Thai children to different formulations of Citrus hystrix essential oils. All strains were incubated for 3 and $6 \mathrm{~h}$ to form biofilms suitable for susceptibility tests. This study also evaluated the inhibitory effect of each oil formulation on growth and biofilm formation of S. mutans (ATCC 25175) using a 96-well polystyrene plate biofilm assay, and analysed the selected formulations that showed the most inhibitory effect from the susceptibility and biofilm assay tests and 3 clinical isolations for further evaluation using fluorescent dyes (SYTO9 and propidium iodide) and confocal laser scanning microscopy (CLSM). Results show that all strains of $S$. mutans tested in this study were sensitive to most of the oil formulations $(\geqslant 99.9 \%)$ when compared to the controls. Most of the oil formulations had an inhibitory effect on $3 \mathrm{~h}$ and $6 \mathrm{~h}$ biofilm formation ( $\geqslant 50 \%$ ) compared to the control. Most of the oil formulations inhibited biofilm formation of the standard strain and all clinical isolates in biofilm assay. All formulae of the essence from the leaf and fruit of $C$. hystrix oil exhibited a significant $(p<0.05)$ inhibitory effect on $S$. mutans and all clinical isolations when compared to the control group and visualized by CLSM. Thus $C$. hystrix essential oils might be an alternative, inexpensive natural medication to prevent dental caries.
\end{abstract}

KEYWORDS: natural essential oil, alternative medicine, dental caries, kaffir lime

\section{INTRODUCTION}

Early childhood caries is still one of the most common chronic diseases worldwide ${ }^{1}$. Even though in Thailand, caries prevalence was reported decreasing recently, it still has a high prevalence rate ${ }^{2,3}$. The cost in providing dental treatment, especially in young children, is increasing in both developed and developing countries ${ }^{4}$.

Biofilm or dental plaque is a complex microbial community composed of numerous aggregated microorganisms that attach to a surface of the teeth and become surrounded by extracellular polymeric matrix. An important characteristic of biofilm is that it is highly tolerant antimicrobial therapeutics ${ }^{5,6}$. The unbalance of microorganism in oral biofilm results in pathological conditions such as dental caries and periodontitis ${ }^{5}$. A current concept of caries development is that the caries process is reversible and can shift back to the balance if it is detected early enough ${ }^{6}$.

Streptococcus mutans is strongly associated with caries $^{7-10}$. It was not only found in a high caries risk group but also in a low risk or cavities-free group $^{11,12}$. The first step in dental plaque formation is the adherence of bacteria to the acquired pellicles, which is a selective process and involves a cascade of bacterial surface adhesion-protein interactions. S. mutans produces water-insoluble polymers (glucan) which aid in the persistent adhesion and colonization on teeth surfaces by the action of glucosyltransferases (GTFase), and it can synthesize intracellular polysaccharide (IPS) which sustains continual acid production in the presence of low exogenous substrate ${ }^{13}$. The adhesion and the production of IPS are important virulence factors in caries development ${ }^{1,13}$. S. mutans does not only play an important role in plaque formation but is also crucial for its development. It is important to counteract the presence of $S$. mutans for more effective prevention of dental caries.

Alternative medicine which uses natural products proven to have anti-cariogenic properties is of great interest in caries research ${ }^{14-17}$. Citrus hystrix DC (kaffir lime or makrut) is a common type of lime that natively grows in SE Asia ${ }^{16}$. In that study, 
C. hystrix oil exerted an antibacterial effect on the 4 species: Bacillus subtilis, Staphylococcus aureus, Escherichia coli, and Salmonella typhimurium ${ }^{16}$. In a later study, three oral spray formulations (with $6 \%$, $10 \%$, and $13 \%$ makrut oil) significantly reduced total facultative bacteria, oral streptococci and $S$. $\mathrm{mu}$ tans from children's toothbrushes ${ }^{17}$. In our preliminary study, we tested the biofilm susceptibility to 5 oral spray formulations (6\%,10\%, 13\% makrut oil, and 4\%, 8\% makrut leaf oil). They showed promising results in inhibiting $3 \mathrm{~h}$ and $6 \mathrm{~h}$ formed biofilm of S. mutans (ATCC 25175) and a few clinical isolates from Thai children. Thus the efficiency of these oil formulations on the inhibition of growth and biofilm formation along with the susceptibility test of $S$. mutans clinical isolations should be further investigated before starting future clinical trials.

Confocal laser scanning microscopy (CLSM) has been used to evaluate bacterial viability in numerous experiments. Fluorescence dyes are applied to the biofilm to differentiate live and dead bacteria, allowing bacteria to be distinguished according to their cytoplasmic membrane permeability. Moreover, CLSM is able to penetrate in a horizontal plane $(X-Y$ axes) and evaluate the depth of biofilm from the outer part to the inner part ${ }^{18-20}$. CLSM can capture a series of image-scans showing changes in the viability of the bacterial cell over time, making the visualization of real-time death of microorganisms possible.

The objectives of this study were (1) to evaluate the susceptibility of $S$. mutans (ATCC 25175) and 9 clinical isolations from Thai children to different formulations of $C$. hystrix essential oils (6\%, 10\%, $13 \%$ makrut oil, 4\%, 8\%, $12 \%$ makrut leaf oil); (2) to evaluate the inhibitory effect of each oil formulation on growth and biofilm formation of S. mutans (ATCC 25175) using 96 well-polystyrene plate biofilm assay; and (3) to analyse the selected formulations with the most inhibitory effect in the susceptibility and biofilm tests, and three clinical isolations for further evaluation using fluorescent dyes and CLSM.

\section{MATERIALS AND METHODS}

\section{Essential oil preparation}

The makrut leaf oil (MLO, batch no. 5209234-1/ 1009 , density $=0.86 \mathrm{~g} / \mathrm{ml}$ ) and makrut oil (MO, batch no. 5209234/1009; density $=0.87 \mathrm{~g} / \mathrm{ml}$ ), were purchased from Thai-China Flavours and Fragrances Co., Ltd., Bangkok. The components of the essential oils were analysed using GC-MS (Auxs) as described previously ${ }^{16}$. Main components in makrut peel and leaves are L-limonene $(40 \%)$ and citronellal (80\%), respectively. Six makrut oil formulations (6\% MO, 10\% MO, 13\% MO, 4\% MLO, $8 \%$ MLO, and $12 \%$ MLO) were prepared. Degradation and taste experiments were performed.

\section{Subject selection and $S$. mutans clinical isolation}

S. mutans clinical isolations were obtained from children (12 males, 5 females aged $3.5-10$ y old) who came to the Paediatric Dental Clinic, Faculty of Dentistry, Chulalongkorn University, Bangkok. For convenience sampling, ethical approval (42/2010) was obtained. After having obtained written and oral consents, oral examination was performed based on World Health Organization definition ${ }^{21}$. $\mathrm{DMFT} / \mathrm{dmft}$ scores were recorded. In brief, stimulated saliva was collected and pooled in an equal proportion, and then cultured on MSA agar (Difco Laboratories, Detroit, MI) containing bacitracin $(0.2 \mathrm{U} / \mathrm{ml}$, Sigma Chemical Co., St Louis, MO), $0.001 \%$ (v/v) tellurite solution (Becton, Dickinson \& Co., Sparks, MD) and 15\% (w/v) sucrose (Sigma Chemical Co.). Ten colonies resembling $S$. mutans from each subject were then transferred to brain heart infusion (BHI) broth and incubated at $37^{\circ} \mathrm{C}$ for $48 \mathrm{~h}$ in an anaerobic jar. DNA samples from 280 isolates were extracted by washing and boiling for $10 \mathrm{~min}$ with TE buffer $(10 \mathrm{mM}$ Tris/ $/ \mathrm{HCl}$, $1 \mathrm{mM}$ EDTA, pH 8.0) ${ }^{22}$. All isolates were then confirmed to be $S$. mutans by biochemical analyses. Two standard strains (Streptococcus mutans ATCC 25175 and Streptococcus sobrinus ATCC 6715) were cultured on BHI agar or broth. Another standard strain, Lactobacillus casei ATCC 36978, was cultured on Rogosa SL agar. All strains were incubated under the same conditions for $18 \mathrm{~h}$.

\section{Bacteria and culture conditions}

Aliquot stocks $\left(-20^{\circ} \mathrm{C}\right)$ of $S$. mutans (ATCC 25175) were grown on BHI and incubated for $48 \mathrm{~h}$ at $37^{\circ} \mathrm{C}$ supplemented with $5 \% \mathrm{CO}_{2}$. After that, $3-5$ colonies were picked, suspended in THB broth (Todd-Hewitt broth, Difco, US) and incubated for $24 \mathrm{~h}$. Aliquot stocks $\left(-20^{\circ} \mathrm{C}\right)$ of a total of nine clinical isolates of $S$. mutans were grown as described above.

\section{Antimicrobial susceptibility}

Minimum inhibitory concentration (MIC) and minimum bactericidal concentration (MBC) determinations were carried out using the Microbroth dilution method. 96-well polystyrene plates were prepared 
by adding tween $20(0.25 \mathrm{v} / \mathrm{v})$. Total volume of BHI broth in each well was $100 \mu$ l. Then, oil formulations were added to each well at the following concentrations: $0.01,0.03,0.06,0.12,0.25,0.5$, and $1 \mu \mathrm{l}(\mathrm{v} / \mathrm{v})$ and controls in each concentration. Cells were diluted with fresh BHI broth to approximately $10^{8}$ to $10^{4}$ colony-forming units (CFU/ml), and incubated at $35^{\circ} \mathrm{C}$ for $18-24 \mathrm{~h}$. The MIC was determined, and then cells from each well were cultured on sheep blood agar and incubated at $35^{\circ} \mathrm{C}$ for $18-24 \mathrm{~h}$ to determine the MBC.

\section{Biofilm susceptibility test}

To examine the effects of various oil formulations on 3 and 6-h-old biofilm and to determine whether different $S$. mutans strains had different susceptibilities to the bactericidal activity of each oil formulation. The biofilm susceptibility test was performed. All strains were diluted with THB broth supplemented with $10 \%(\mathrm{w} / \mathrm{v})$ sucrose. Starting with a cell density of $10^{8} \mathrm{CFU} / \mathrm{ml}, 2 \mathrm{ml}$ of diluted cells were transferred into a new tube and incubated for 3 and $6 \mathrm{~h}$. After incubation, planktonic cells were removed by washing 3 times with sterile water. Then $2 \mathrm{ml}$ of the essential oil formulation to be tested was added to the same tube. After $1 \mathrm{~min}$, the oil was washed out, and 10 of $2 \times 2 \mathrm{~mm}$ sterile beads and $2 \mathrm{ml}$ of normal saline solution (PBS) were added and vortexed for $1 \mathrm{~min}$. Then $20 \mathrm{ml}$ of the remaining solution was pipetted and dropped on BHI agar. CFU were obtained by counting outgrowing on the plates. All experiments were done in triplicate. The percentage of outgrowing colonies was counted and compared to that of the control samples. The effective bactericidal effect was significant at more than $99.9 \%$ compared to the control.

\section{Biofilm inhibition assay}

Stimulated pooled saliva was obtained from 5 volunteers collected after tooth brushing for more than $6 \mathrm{~h}$ and chewed paraffin to collect the saliva. Pooled saliva was centrifuged and diluted to 1:10 by PBS buffer and filtered (filter paper, Millipore, USA). Each well containing $100 \mu \mathrm{l}$ diluted saliva was incubated at $37^{\circ} \mathrm{C}$ for $24 \mathrm{~h}$, then the saliva was rinsed off. All strains were grown in TH broth for $24 \mathrm{~h}$ and diluted with 5\% (w/v) sucrose to a cell density of $10^{5} \mathrm{CFU} / \mathrm{ml}$. Each well contained $200 \mu \mathrm{l}$ solution. Then, $5 \mu \mathrm{l}$ of tween $(25 \mu \mathrm{l} / 100 \mu \mathrm{l} \mathrm{v} / \mathrm{v})$, oil formulations were added and mixed by pipetting. All experiments were done in triplicate. After $18 \mathrm{~h}$ incubation, growth was measured using micro-plate reader at the optimal density of $595 \mathrm{~nm}$ (Microplate
Spectrophotometer, Biotek, USA). Then, samples were stained with $100 \mu \mathrm{l}$ crystal violet $0.05 \%$ (w/v) for $15 \mathrm{~min}$ and rinsed with water, and placed at room temperature for $1 \mathrm{~h}$. Biofilm formation was read by adding $150 \mu \mathrm{l} /$ well $90 \%$ ethanol and put on shaker at slow speed in order to remove all planktonic cells. The mean percent inhibition was calculated from replicate tests, and the IC50 was determined as a concentration of the sample which inhibited $50 \%$ of biofilm formation in comparison to the control.

\section{Saliva-coated 24-well plates and biofilm assay}

A condition was selected from the biofilm inhibition assay which gave $>50 \%$ inhibition rate when compared with control (MBIC). Cells were inoculated in THB broth and incubated for $24 \mathrm{~h}$. This was diluted with THB broth supplied with 5\% sucrose to obtain a cell concentration of $10^{8}$ and pipetted into the 24-well polystyrene plate. Each well contained $300 \mu \mathrm{l}$ was incubated at the same condition for $24 \mathrm{~h}$. After that all solutions were removed by pipetting and each well rinsed with PBS 3 times to remove non-adherent bacteria on the cover glass. Then $300 \mu \mathrm{l}$ of diluted makrut peel oil and makrut leaf oil with tween20 ( $4 \mu \mathrm{l} / 300 \mu \mathrm{l}$ per volume) was pipetted into each well. After five minutes of incubation, all solution was discarded and the well rinsed with PBS 3 times. Then $300 \mu$ l of of PBS were added into each well to prevent biofilm dryness.

\section{Fluorescence staining and CLSM}

Live cells will exhibit green colour (due to staining with SYTO9), whereas dead cells will exhibit red colour (due to staining with propidium iodide). CLSM has been used to evaluate bacterial viability in biofilms. The most suitable concentration for the fluorescence staining with syto 9 and propidium iodide (syto 9 and propidium iodide, L7012 LIVE/DEAD BacLight bacterial viability kit for microscopy and quantitative assays, Invitrogen, USA) was determined using autoclave distilled water. The fluorescence staining was tested in $1 \mathrm{ml}$ micro centrifuge tubes in dilutions of $1 / 10,1 / 100,1 / 1000$. $6 \mu \mathrm{l}$ of each test staining solution was pipetted into different wells of 24-well polystyrene plate, mixed gently with the pipette not to disturb the biofilm containing the bacteria. The samples were stored in the dark for 15 min and then 1-4 $\mu$ l of stained biofilm were analysed under CLSM (live cell fluorescent imaging system IX83ZDC CLSM, IX83ZDC, Olympus, Japan). Used lens at $60 \times$ green narrow 
Table 1 Minimum inhibitory concentration (MIC) and minimum bactericidal concentration (MBC) of Citrus hystrix oil formulations on the inhibition of three bacteria standard strains.

\begin{tabular}{|c|c|c|c|c|c|c|c|c|c|c|c|c|}
\hline \multirow[t]{2}{*}{ Bacterial strains } & \multicolumn{2}{|c|}{ 4\% MLO } & \multicolumn{2}{|c|}{$6 \% \mathrm{MO}$} & \multicolumn{2}{|c|}{$12 \%$ MLO } & \multicolumn{2}{|c|}{$10 \% \mathrm{MO}$} & \multicolumn{2}{|c|}{$13 \% \mathrm{MO}$} & \multicolumn{2}{|c|}{ 8\% MLO } \\
\hline & MIC & MBC & MIC & MBC & MIC & $\mathrm{MBC}$ & MIC & $\mathrm{MBC}$ & MIC & MBC & MIC & MBC \\
\hline S. mutans ATCC 25175 & 0.156 & 0.625 & 0.046 & 0.093 & 2.5 & $>2.5$ & 0.05 & 0.084 & $>2.5$ & $>2.5$ & 0.2 & 0.52 \\
\hline S. sobrinus ATCC 6715 & 0.312 & 0.625 & 1 & 0.375 & $>2.5$ & $>2.5$ & 1 & 0.254 & $>2.5$ & $>2.5$ & 0.251 & 0.5 \\
\hline L. casei ATCC 36978 & 1.25 & 2.5 & 0.75 & 1.5 & $>2.5$ & $>2.5$ & 0.75 & 1 & $>2.5$ & $>2.5$ & 1 & 2.5 \\
\hline
\end{tabular}

MIC and MBC calculated as $(\% \mathrm{v} / \mathrm{v})$.

48\%, PJ 46\%, and PH 37\%. The best condition was the fluorescence staining concentration 1:10.

\section{Statistic analysis}

All experiments were performed in triplicate. Data was expressed as mean \pm SD. The differences between means of the experiment and control groups were evaluated by the Student's $t$-test $(p<0.05)$. Data were analysed using SPSS 18 (Chicago, IL).

For the determination of live/dead cells at the excitation wavelength of $485 \mathrm{~nm}$ the green emission at $530 \mathrm{~nm}$ (live cells) and the red emission at $630 \mathrm{~nm}$ (dead cells) were measured and their ratio calculated. Each well was measured 3 times. Mean and standard deviation were calculated, and the Kruskal-Wallis Test (Bonferroni and Dunn Test) used to compare experimental and control groups (significance at 95\%).

\section{RESULTS}

\section{MIC and MBC and biofilm inhibition assay}

The MIC of makrut leaf oil and makrut oil were in the range of $0.06-68 \mathrm{mg} / \mathrm{ml}$ and $0.03-17.4 \mathrm{mg} / \mathrm{ml}$, respectively (Table 1 ). Although the MIC and MBC varied among tested bacteria, the MIC in most cases was equivalent to $\mathrm{MBC}$ indicating a bactericidal action of the oil.

\section{Biofilm susceptibility test}

All strains of $S$. mutans tested in this study were sensitive to most of oil formulations ( $\geqslant 99.9 \%)$ when compared to the controls. Most of oil formulations had an inhibitory effect on $3 \mathrm{~h}$ and $6 \mathrm{~h}$ biofilm formation $(\geqslant 50 \%)$ compared to the control (Fig. 1). Higher concentration of oil formulations were used to demonstrate antibacterial effects on 6-h-old biofilm as compared to the 3-h-old biofilm (Table 2 and Table 3).

\section{Biofilm inhibition assay}

Most of oil formulations had an inhibitory effect on biofilm formation $(\geqslant 50 \%)$ compared to the control

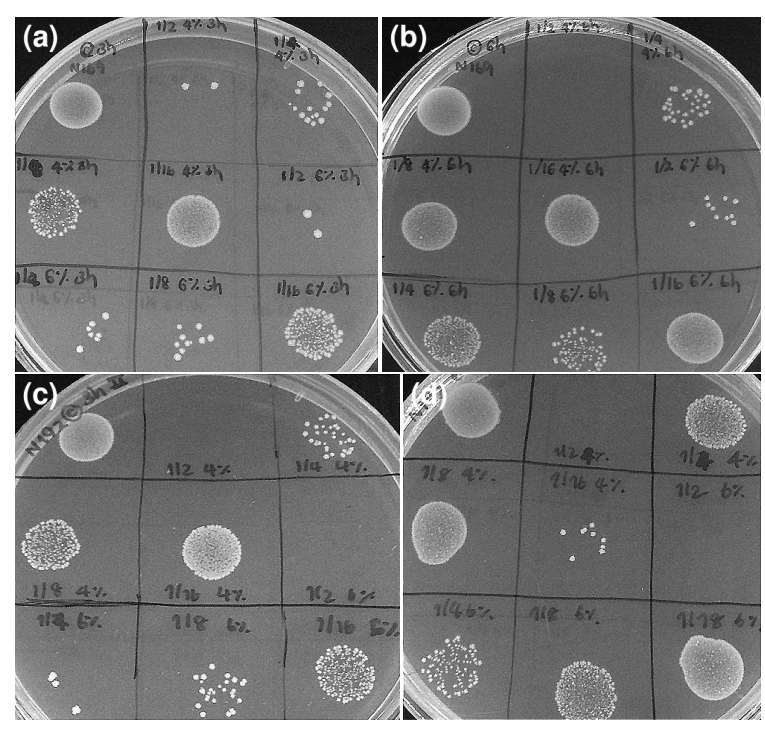

Fig. 1 (a) The 3-h-preformed biofilm by $S$. mutans clinical isolate strain N169 was inhibited by 4\% MLO and 6\% MO in all dilutions, except 4\% MLO $1 / 8$ and $1 / 16$ dilutions and 6\% MO 1/16 dilution, (b) the 6-h-preformed biofilm by $S$. mutans clinical isolate strain N169 was inhibited by 4\% MLO and 6\% MO in all dilutions, except 4\% MLO 1/8 and $1 / 16$ dilutions and $6 \% \mathrm{MO} 1 / 4$ and $1 / 16$ dilutions, (c) the 3-h-preformed biofilm by $S$. mutans clinical isolate strain N192 was inhibited by 4\% MLO and 6\% MO in all dilutions except 4\% MLO $1 / 8$ and 1/16 dilution and $6 \%$ MO $1 / 8$ and $1 / 16$ dilutions, and (d) the 6-h-preformed biofilm by $S$. mutans clinical isolate strain N192 was inhibited by 4\% MLO and 6\% MO in all dilutions except $4 \%$ MLO $1 / 4$ and $1 / 8$ dilutions and $6 \%$ MO 1/8 and 1/16 dilutions.

when stained with crystal violet solution $0.05 \%$ (w/v) (Fig. 2). The inhibitory effect was dosedependent at $10^{4} \mathrm{CFU} / \mathrm{ml}$. However, the effects on growth were quite variable. Nevertheless, our study showed that all essential oils tested were active against the planktonic growth and biofilm of S. mutans. Planktonic growth inhibition was always 
Table 2 The inhibition effect of the makrut oil oral sprays at different concentrations on 3-h-preformed biofilm formation by $S$. mutans (ATCC 25175) and several clinical isolations (N013, N169, 089, N202, N109, N192, N006, and N143).

\begin{tabular}{|c|c|c|c|c|c|}
\hline \multirow[t]{2}{*}{ Strain } & \multirow[t]{2}{*}{ Formulation } & \multicolumn{4}{|c|}{ Dilution } \\
\hline & & $1 / 2$ & $1 / 4$ & $1 / 8$ & $1 / 16$ \\
\hline N013 & $6 \% \mathrm{MO}$ & + & + & + & - \\
\hline N169 & $6 \% \mathrm{MO}$ & + & + & + & - \\
\hline N89 & $6 \% \mathrm{MO}$ & + & + & + & - \\
\hline N202 & $6 \% \mathrm{MO}$ & + & + & + & - \\
\hline N109 & $6 \% \mathrm{MO}$ & + & + & - & - \\
\hline N192 & 6\% MO & + & + & - & - \\
\hline ATCC 25175 & $10 \% \mathrm{MO}$ & + & + & + & + \\
\hline N100 & $10 \% \mathrm{MO}$ & + & + & + & + \\
\hline N006 & $10 \% \mathrm{MO}$ & + & + & + & + \\
\hline N013 & $10 \% \mathrm{MO}$ & + & + & + & + \\
\hline N169 & $10 \% \mathrm{MO}$ & + & + & + & + \\
\hline N89 & $10 \% \mathrm{MO}$ & + & + & - & - \\
\hline N202 & $10 \% \mathrm{MO}$ & + & + & + & + \\
\hline N143 & $10 \% \mathrm{MO}$ & + & + & + & + \\
\hline ATCC 25175 & $13 \% \mathrm{MO}$ & + & + & + & - \\
\hline ATCC 25175 & 4\% MLO & - & - & - & - \\
\hline N013 & 4\% MLO & + & + & - & - \\
\hline N169 & 4\% MLO & + & + & - & - \\
\hline N89 & 4\% MLO & + & - & - & - \\
\hline N202 & 4\% MLO & + & - & - & - \\
\hline N109 & 4\% MLO & + & - & - & + \\
\hline N192 & 4\% MLO & + & + & - & - \\
\hline N109 & 8\% MLO & + & + & + & + \\
\hline N192 & 8\% MLO & + & + & + & + \\
\hline ATCC 25175 & $12 \% \mathrm{MLO}$ & + & + & - & - \\
\hline N100 & $12 \% \mathrm{MLO}$ & + & + & - & - \\
\hline N143 & $12 \%$ MLO & + & + & - & - \\
\hline N006 & $12 \% \mathrm{MLO}$ & + & + & + & - \\
\hline
\end{tabular}

$(+)=$ kill $\geqslant 99.9 \%$ when compared to control

$(-)=$ kill $<99.9 \%$ when compared to control

lower than biofilm inhibition (Fig. 3).

\section{Saliva-coated 24-well plate and biofilm assay and fluorescence staining and CLSM}

For the inhibition of $S$. mutans (ATCC 25175) at cells concentration of $10^{8} \mathrm{CFU} / \mathrm{ml}, 12 \% \mathrm{MLO}$ showed the highest inhibition rate which gave the lowest percent of live cells $(15 \pm 1 \%)$ followed by $10 \% \mathrm{MO}(20 \pm 1 \%)>13 \% \mathrm{MO}(22 \pm 2 \%)>8 \%$ MLO $(27 \pm 2 \%)>6 \%$ MO $(31 \pm 2 \%)>4 \%$ MLO (40 $\pm 6 \%$, Fig. 4). All formulae showed significantly ( $p=0.005)$ different inhibition rate compared to control in the Kruskal-Wallis Test. When compared between each formulae, 13\% MO, 12\% MLO, 10\%
Table 3 The inhibition effects of the makrut oil oral sprays at different concentrations on 6-h-preformed biofilm formation by $S$. mutans (ATCC 25175) and several clinical isolations (N013, N169, 089, N202, N109, N192, N006, and N143).

\begin{tabular}{|c|c|c|c|c|c|}
\hline \multirow[t]{2}{*}{ Strain } & \multirow[t]{2}{*}{ Formulation } & \multicolumn{4}{|c|}{ Dilution } \\
\hline & & $1 / 2$ & $1 / 4$ & $1 / 8$ & $1 / 16$ \\
\hline N013 & $6 \% \mathrm{MO}$ & + & - & - & - \\
\hline N169 & $6 \% \mathrm{MO}$ & + & - & + & - \\
\hline N89 & $6 \% \mathrm{MO}$ & + & + & + & - \\
\hline N202 & $6 \% \mathrm{MO}$ & + & - & - & - \\
\hline N109 & $6 \% \mathrm{MO}$ & + & + & - & - \\
\hline N192 & $6 \% \mathrm{MO}$ & + & + & - & - \\
\hline ATCC 25175 & $10 \% \mathrm{MO}$ & + & + & - & - \\
\hline N100 & $10 \% \mathrm{MO}$ & + & - & - & - \\
\hline N006 & $10 \% \mathrm{MO}$ & + & - & + & - \\
\hline N013 & $10 \% \mathrm{MO}$ & + & + & - & - \\
\hline N169 & $10 \% \mathrm{MO}$ & + & + & + & - \\
\hline N89 & $10 \% \mathrm{MO}$ & + & + & + & + \\
\hline N202 & $10 \% \mathrm{MO}$ & + & + & + & - \\
\hline N143 & $10 \% \mathrm{MO}$ & & & & \\
\hline ATCC 25175 & $13 \% \mathrm{MO}$ & + & + & - & - \\
\hline ATCC 25175 & 4\% MLO & + & - & - & - \\
\hline N013 & 4\% MLO & + & + & - & - \\
\hline N169 & 4\% MLO & + & + & - & - \\
\hline N89 & 4\% MLO & + & + & - & - \\
\hline N202 & 4\% MLO & + & - & - & - \\
\hline N109 & 4\% MLO & + & - & - & - \\
\hline N192 & 4\% MLO & + & - & - & + \\
\hline N109 & 8\% MLO & + & + & + & + \\
\hline N192 & 8\% MLO & + & + & + & + \\
\hline ATCC 25175 & $12 \% \mathrm{MLO}$ & + & + & - & - \\
\hline N100 & $12 \%$ MLO & - & - & - & - \\
\hline N143 & $12 \% \mathrm{MLO}$ & & & & \\
\hline N006 & $12 \% \mathrm{MLO}$ & + & - & - & - \\
\hline
\end{tabular}

$(+)=$ kill $\geqslant 99.9 \%$ when compared to control

$(-)=$ kill $<99.9 \%$ when compared to control

MO, 8\% MLO, and 6\% MO showed a higher biofilm inhibition rate significantly ( $p=0.013$ ) when compared to 4\% MLO using the multiple comparison test (Bonferroni and Dunn Test) at the significant level of 0.05 .

For the inhibition of $S$. mutans clinical isolate N89 at a cell concentration of $10^{8} \mathrm{CFU} / \mathrm{ml}$, $10 \% \mathrm{MO}$ showed the highest inhibition rate which gave the lowest rate (lowest percent of live cells, $24 \pm 3 \%)$ followed by $12 \%$ MLO $(28 \pm 0 \%)>13 \%$ MO $(29 \pm 5 \%)>6 \%$ MO $(30 \pm 3 \%)>8 \%$ MLO $(31 \pm 4 \%)>4 \%$ MLO (44 $\pm 0 \%$, Fig. 5). All formulae showed significantly different inhibition rates ( $p=0.029$ ) when compared to control (Kruskal- 


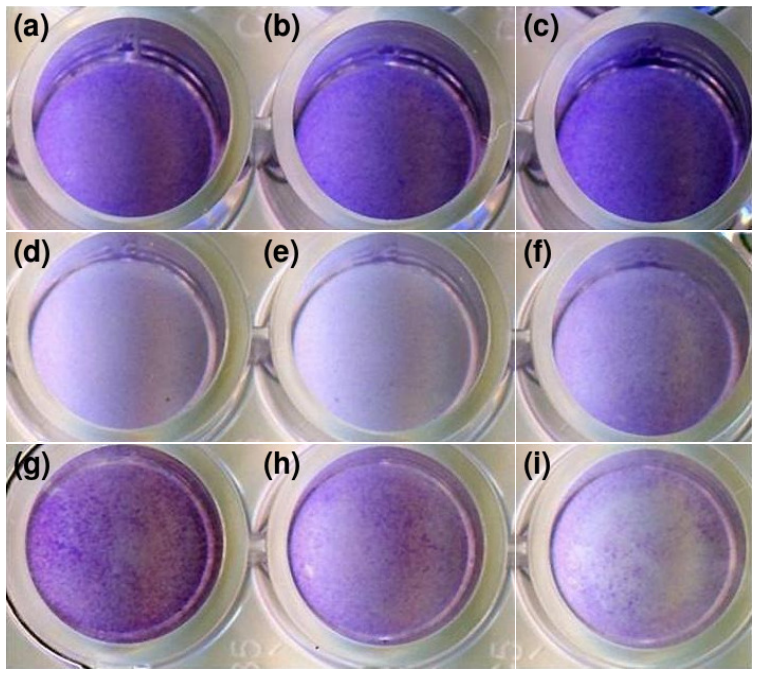

Fig. 2 S. mutans ATCC 25175 biofilm formation after staining with crystal violet solution $0.05 \%(\mathrm{w} / \mathrm{v})$. C. hystrix oil formulation in spray form (12\% MLO) was added into wells containing $10^{8} \mathrm{CFU} / \mathrm{ml}$ and incubated for $24 \mathrm{~h}$. Higher concentrations of oil formulations were used for demonstrated biofilm formation inhibition effect in dose dependence: (a)-(c) control, (d) $4 \%$, (e) $3 \%$, (f) $2 \%$, (g) $0.25 \%$ (h) $0.5 \%$, (i) $1 \%$.

Wallis test at $p<0.05)$. 4\% MLO showed the lowest biofilm inhibition rate significantly $(p=0.001)$ when compared to $10 \% \mathrm{MO}$ and $12 \%$ MLO using multiple Bonferroni and Dunn Test at $p<0.05$. The other formulations did not show significant differences.

For the inhibition of $S$. mutans clinical isolate N109 at a cell concentration of $10^{8} \mathrm{CFU} / \mathrm{ml}, 10 \%$ MO showed the highest inhibition rates which gave the lowest percent of live cells $(33 \pm 3 \%)$ followed by $13 \% \mathrm{MO}(35 \pm 4 \%)>8 \% \mathrm{MLO}(42 \pm 2 \%)>6 \%$ MO $(45 \pm 0 \%)>4 \%$ MLO $(52 \pm 9 \%)>12 \%$ MLO (54 $\pm 3 \%$, Fig. 6). All formulae showed significantly different inhibition rate $(p=0.008)$ when compared to control (Kruskal-Wallis test at $p<0.05$ ), whereas comparisons between each formulation showed no significant differences.

For the inhibition of $S$. mutans clinical isolate $\mathrm{N} 143$ at a cell concentration of $10^{8} \mathrm{CFU} / \mathrm{ml}, 13 \%$ MO showed the highest inhibition rates which gave the lowest percent of live cells (15 $\pm 4 \%)$ followed by $12 \%$ MLO $(17 \pm 0 \%)>8 \%$ MLO $(19 \pm 3 \%)>$ $10 \% \mathrm{MO}(21 \pm 10 \%)>4 \%$ MLO $(28 \pm 3 \%)>6 \%$ MO (41 $\pm 7 \%$, Fig. 7). All formulae showed significantly different inhibition rates $(p=0.031)$ when compared to control (Kruskal-Wallis test at $p<$
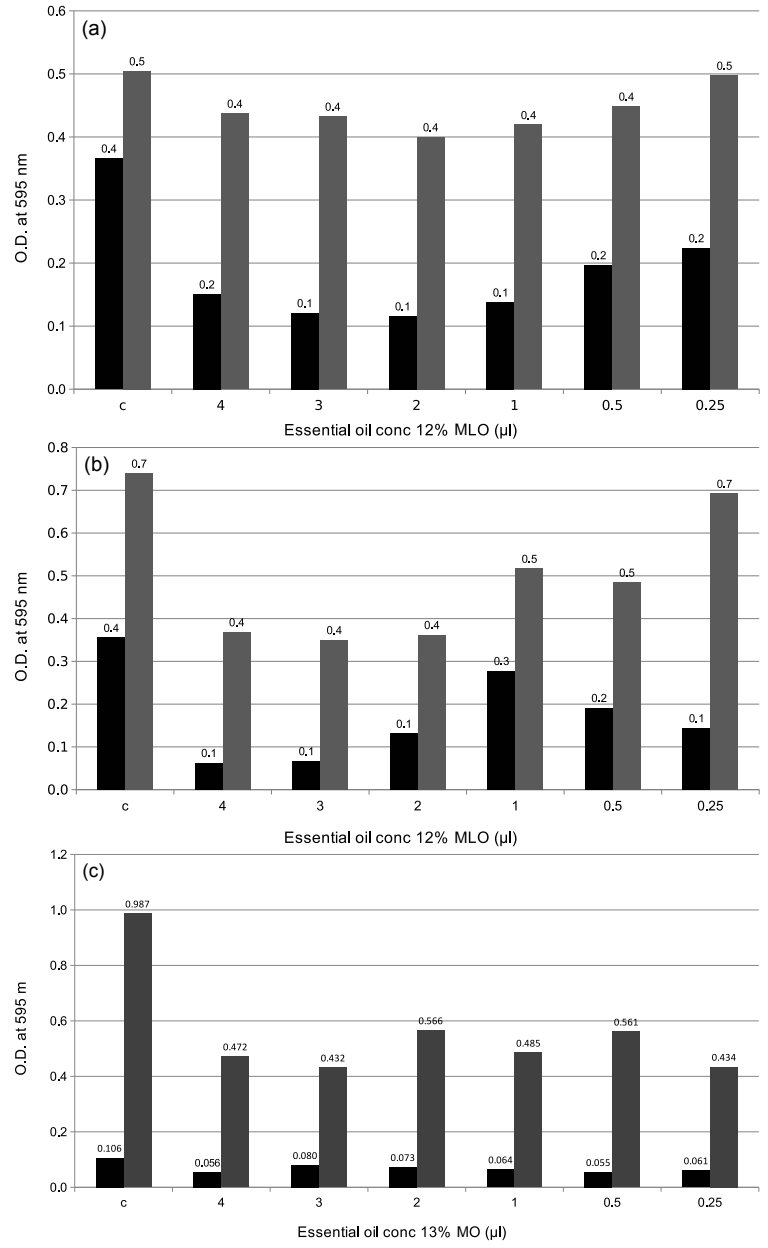

Fig. 3 (a) Growth and biofilm formation of $S$. mutans ATCC 25175 at cell concentration of $10^{8} \mathrm{CFU} / \mathrm{ml}$ were inhibited at all 12\% MLO essential oil concentrations, (b) growth and biofilm formation of $S$. mutans ATCC 25175 at cell concentration of $10^{4} \mathrm{CFU} / \mathrm{ml}$ were inhibited at all 12\% MLO essential oil concentrations, (c) growth and biofilm formation of $S$. mutans ATCC 25175 at cell concentration of $10^{6} \mathrm{CFU} / \mathrm{ml}$ were inhibited at all $13 \%$ MO essential oil concentrations.

0.05), whereas comparison between each formulation showed no significant differences.

\section{DISCUSSION}

To test the efficacy of antibacterial formulations on one bacterial species constitutes an important pre-requisite before testing its effects on preparations containing several bacterial species. Besides, biofilms formed by just one organism are advantageous to study the mechanisms of action of antibacterial therapeutic agents. In the present work, the oil formulations 10\% MO and 12\% MLO 

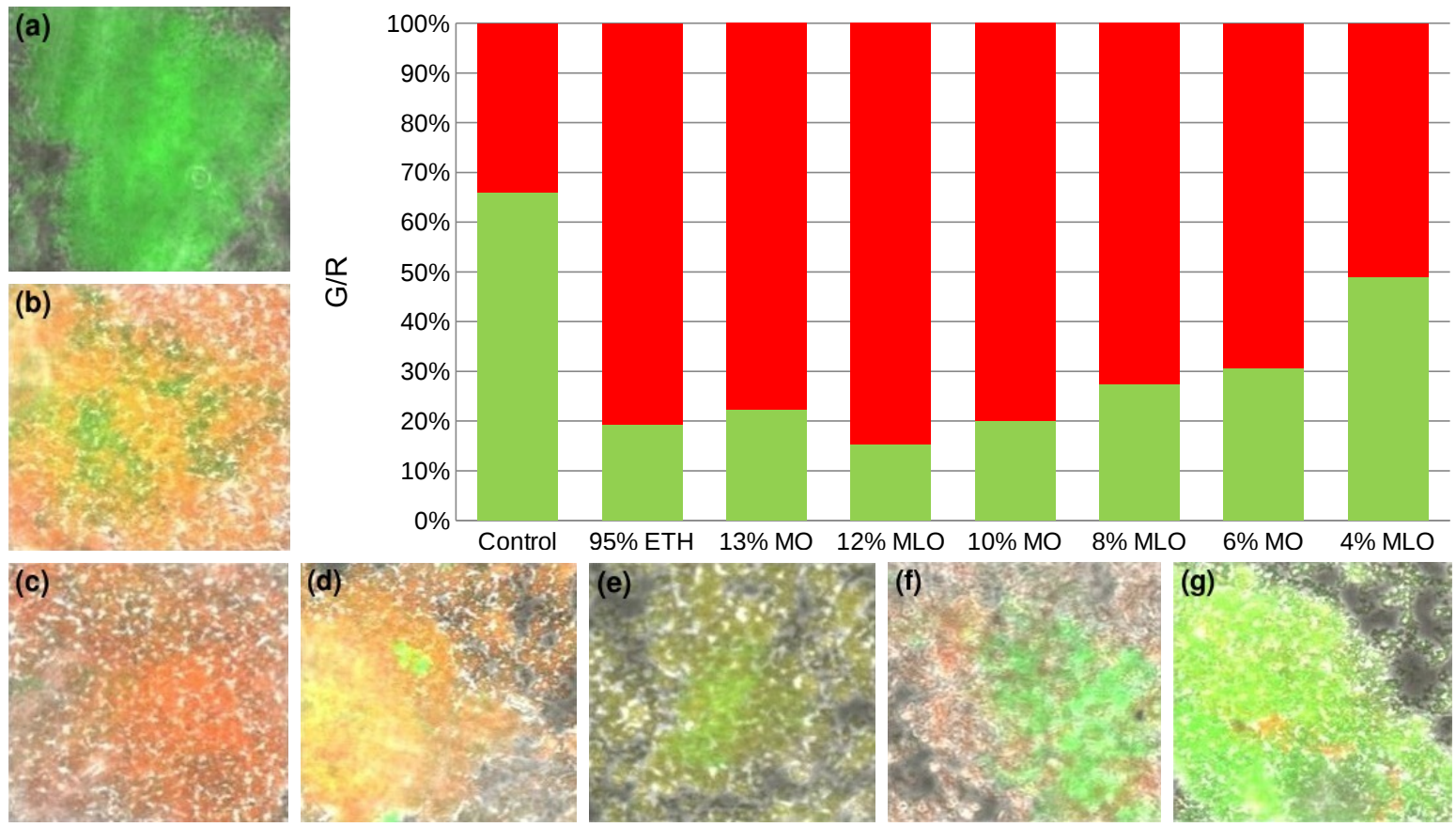

Fig. 4 24-h S. mutans (ATCC 25175) biofilm formation. Live cells were stained and exhibited green fluorescence whereas dead cells exhibited red fluorescence under CLSM: (a) control, (b) 13\% MO, (c) 12\% MLO, (d) 10\% MO, (e) $8 \% \mathrm{MLO}$, (f) $6 \% \mathrm{MO}$, (g) $4 \% \mathrm{MLO}$. The graph represents the percent reduction in variable cells in the $S$. mutans biofilm using the different spray formulations.

effectively inhibited growth and biofilm formation of Streptococcus mutans (ATCC 25175). The study evaluated the sensitivity of $S$. mutans (ATCC 25175) and four clinical isolations from Thai children to different formulations of $C$. hystrix essential oils showing clear antibacterial activity in view of possible future clinical trials. Also, other oil formulations were tested and showed bactericidal effects on $6 \mathrm{~h}$ biofilm when compared to $3 \mathrm{~h}$ biofilm. This result is in accord with the existence of three different stages of biofilm formation with accumulation at $0-5 \mathrm{~h}$, active accumulation at 4-20 h, and a slower accumulation with plateau-phase ${ }^{23}$. The $3 \mathrm{~h}$ biofilm was in the first stage, whereas the $6 \mathrm{~h}$ biofilm was in the second stage. The $6 \mathrm{~h}$ biofilm was more complex and resistant because of a rapid increase in adherence. In addition, our study tested higher concentrations of oil formulations than those used to inactivate the bacterial film. We demonstrated an excellent activity of makrut leaf oil and makrut oil against different strains of $S$. mutans at various oil concentrations. There are many possibilities to demonstrate varying sensitivities with different strains of S. mutans. Also, different oil formulations resulted in different levels of genes expression leading to differences in aciduric and biofilm formation ${ }^{12,24-26}$

This study also tested the inhibitory effect on growth and biofilm formation of $S$. mutans (ATCC 25175). In our study, most of the oil formulations exhibited an inhibitory effect on biofilm formation. Generally, biofilm formation at a cell density of $10^{8} \mathrm{CFU} / \mathrm{ml}$ were not inhibited but most oil formulations inhibited biofilm formation at $10^{5}$ and $10^{4} \mathrm{CFU} / \mathrm{ml}$ (data not showed). Particularly, at the cell density of $10^{4} \mathrm{CFU} / \mathrm{ml}$, the oil formulation 6\% MO, 4\% MLO and 12\% MLO demonstrated a dose-dependent inhibition of biofilm formation. The mechanism for the observed inhibitory effect of these essential oils on biofilm formation is unknown; however, it is likely that the oils inhibit bacterial growth, biofilm formation, acid production, and/or adhesion by interfering with the lipids of the bacterial membranes. The active ingredients that exert antibacterial effects in $C$. hystrix essential oils are the antioxidants alpha-terpineol and citronellal. Also, other oil ingredients such as $t$-farnesol showed a bactericidal effect on $S$. mutans. It had no direct bactericidal effect but are known to interfere with adhesion and polysaccharide production related to 

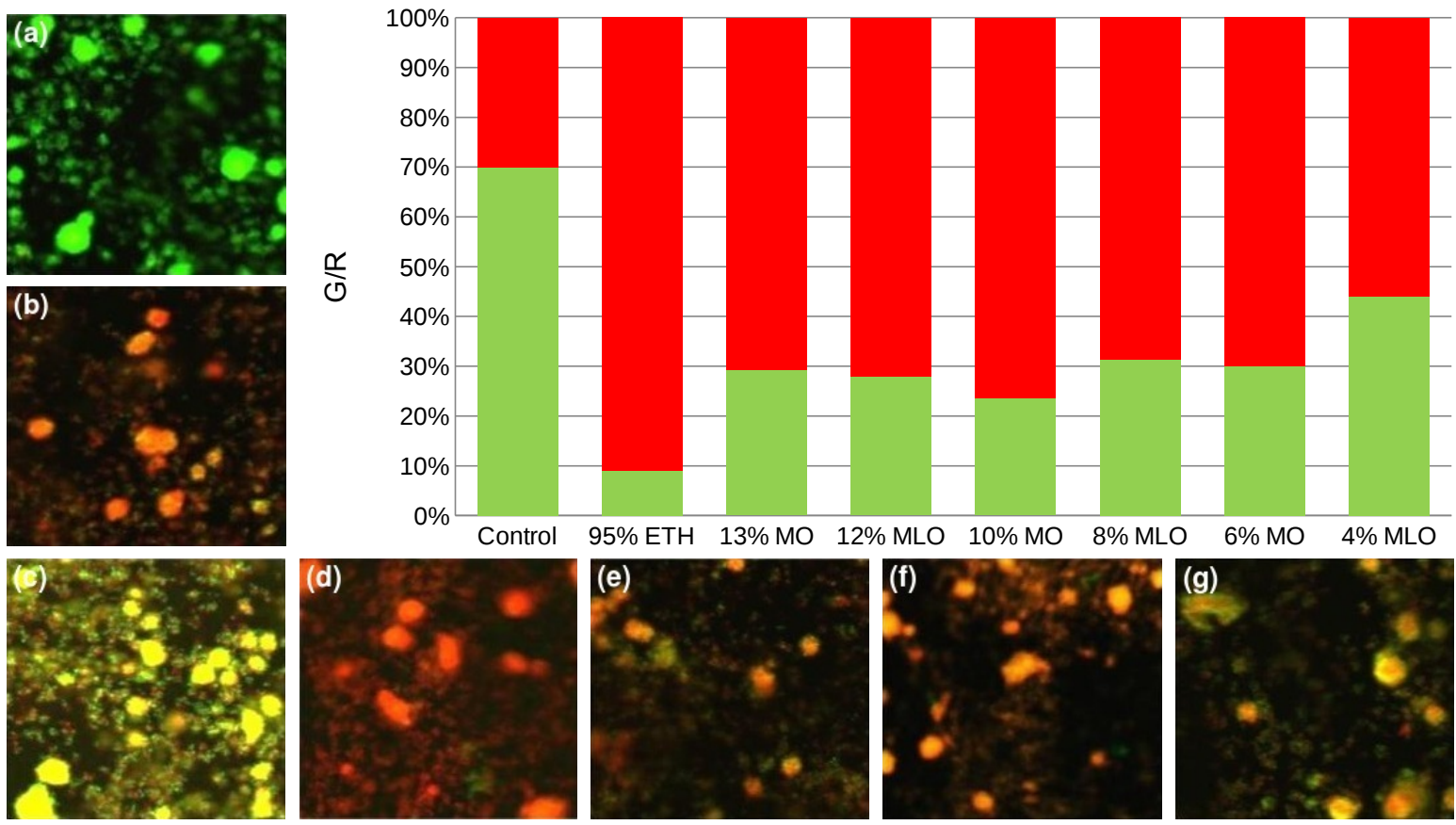

Fig. 5 Same as Fig. 4, for S. mutans clinical isolate N89. N89 showed more cell cluster in biofilm when compared with the standard strain.
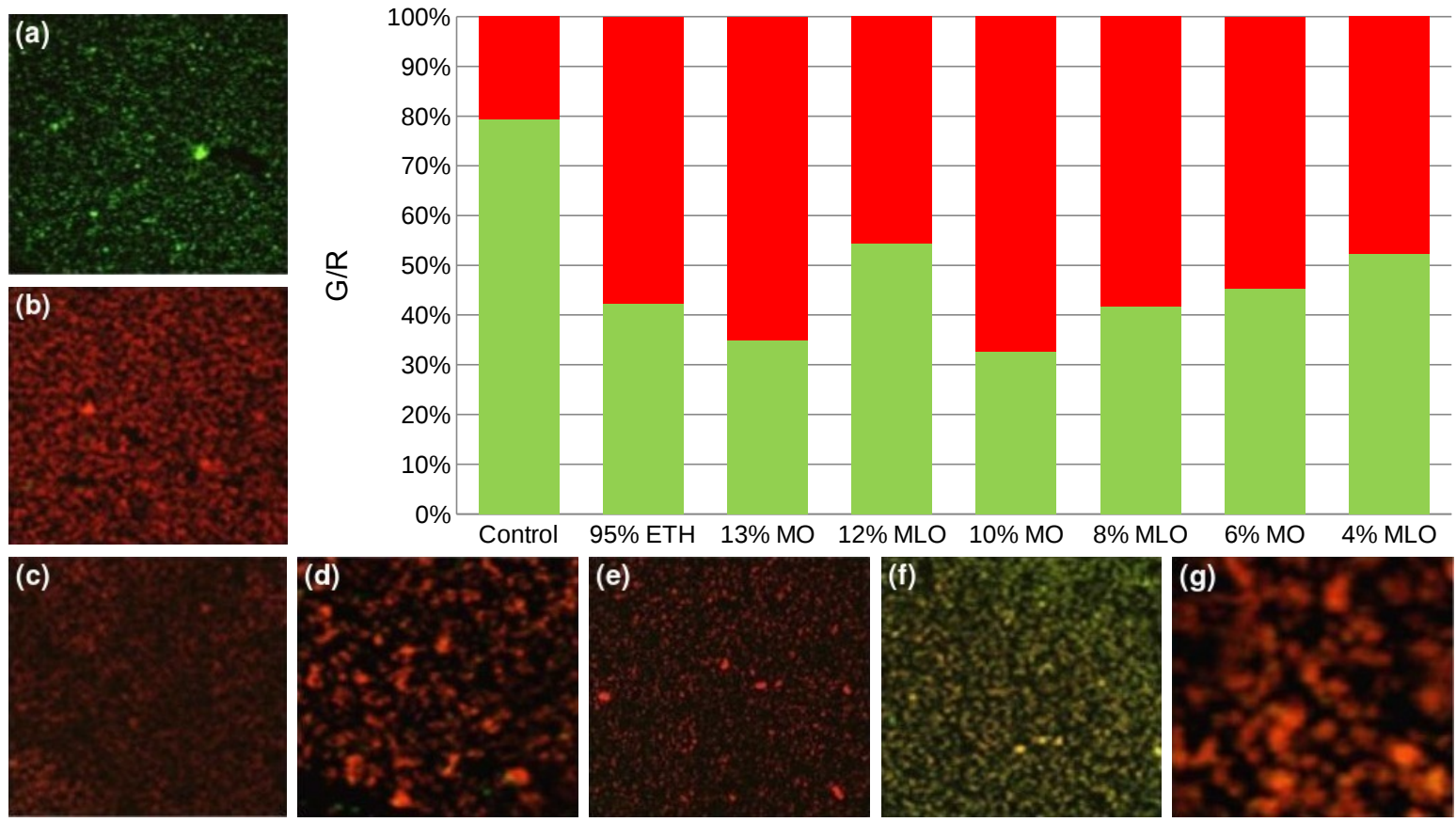

Fig. 6 Same as Fig. 4, for S. mutans clinical isolate N109. N109 showed less cell cluster in biofilm when compared with the standard strain and N89.

the biofilm formation ${ }^{25}$. The hydrophobicity of the essential oils might enable them to destroy the lipid components of the bacterial cell membranes rendering them permeable and leading to cell lysis.
The exact mechanism of $C$. hystrix essential oils needs further study.

We showed here that oral oil formulations $6 \%$ MO, $10 \% \mathrm{MO}, 13 \% \mathrm{MO}$, 4\% MLO, $8 \%$ MLO, and $12 \%$ 

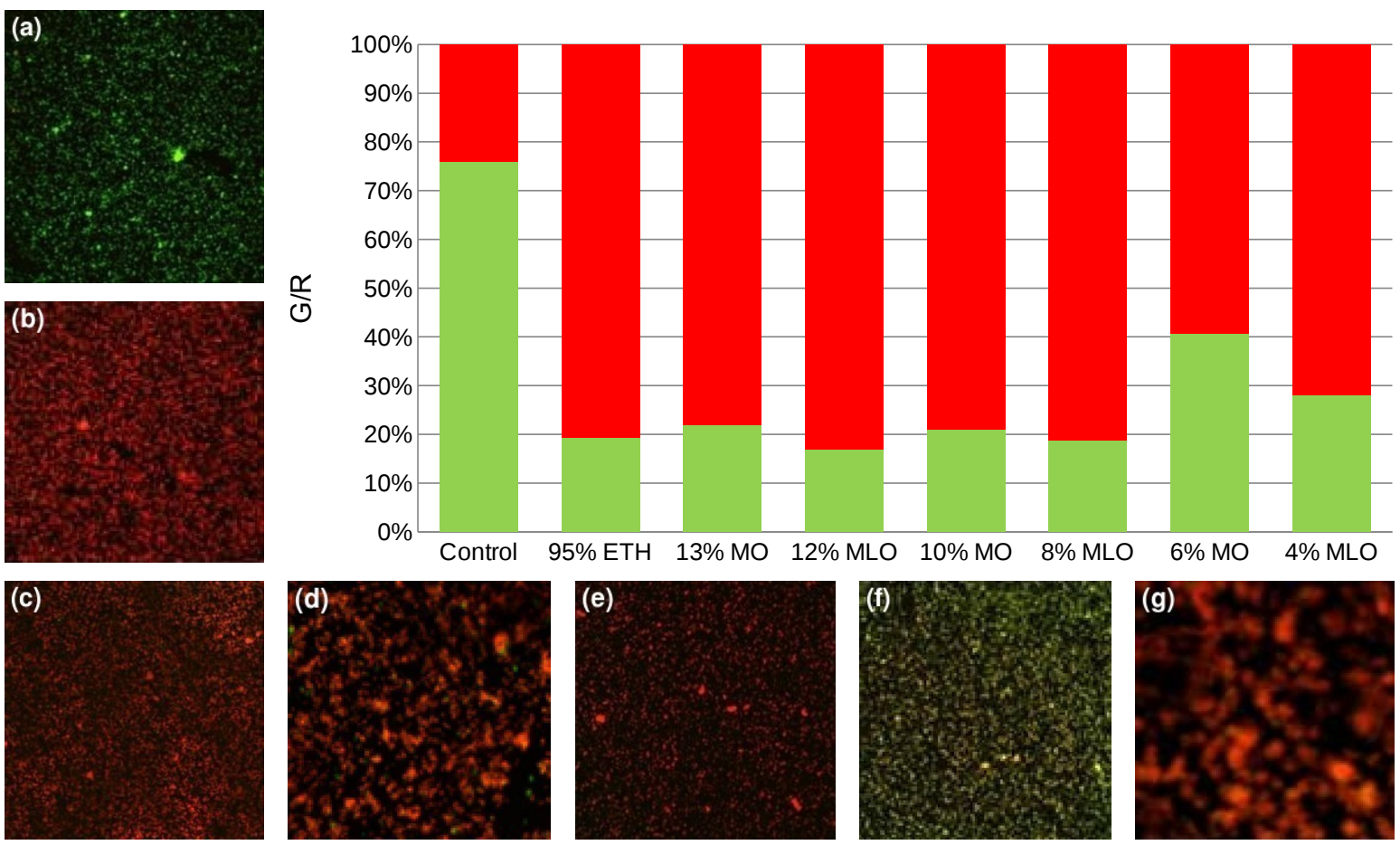

Fig. 7 Same as Fig. 4, for S. mutans clinical isolate N143. N143 showed similar cell cluster in biofilm as N109 but less cell cluster when compared with N89.

MLO could inhibit biofilm formation using $S$. mutans (ATCC 25175) and 3 clinical isolates (N89, N109 and N143), fluorescent staining to distinguish live and dead cells and their quantification by CLSM. The results showed that all six oral spray formulations significantly inhibited biofilm formation and disrupted the biofilm structure. This result is similar to the study by Nuryastuti et al who studied the inhibitory effects of cinnamon oil on Staphylococcus epidermidis biofilm ${ }^{26}$.

\section{Conclusion}

In conclusion, oil formulations: $6 \% \mathrm{MO}, 10 \% \mathrm{MO}$, $13 \% \mathrm{MO}, 4 \% \mathrm{MLO}$, and 8\% MLO effectively inhibit biofilm formation by $S$. mutans and biofilm susceptibility, suggesting that it may be worthwhile to consider them for further studies and a clinical trial to test their therapeutic effectiveness. These essential oils may be important for clinical applications, for example, in slow-release and spray forms for the prevention and treatment of dental caries. As shown here, $C$. hystrix oil formulations inhibited growth and biofilm formations of $S$. mutans in saliva-coated polystyrene plates, and oral sprays provided significant inhibition at high bacterial cell density. From this, it appears that these formulations (after having tested their iniquity on normal human epithelium cells) could be proposed for a clinical trial in order to test their effectiveness in human patients. In particular, such clinical studies are needed to verify the efficacy of these formulations against early childhood caries.

Acknowledgements: This project was partially supported by the Faculty of Dentistry, Mahidol University. The authors would like to thank Artit Khlao-pimai for helping with the microbiological assays and Chulalak Komoltri of Siriraj Hospital, for the statistical assessment.

\section{REFERENCES}

1. Tanzer JM, Livingston J, Thompson AM (2001) The microbiology of primary dental caries in humans. J Dent Educ 65, 1028-37.

2. Dental Health Devision Ministry of Public Health Thailand (2007) The 6th National Dental Health Status Survey, 2006-2007, Dental Health Division, Nonthaburi.

3. Dental Health Division Ministry of Public Health Thailand (2012) The 7th National Dental Health Status Survey, Dental Health Division, Nonthaburi.

4. Evans CA, Kleinman DV (2000) The surgeon general's report on America's oral health: opportunities for the dental profession. J Am Dent Assoc 131, $1721-8$. 
5. Marsh PD (2004) Dental plaque as a microbial biofilm. Caries Res 38, 204-11.

6. Featherstone JD (2004) The continuum of dental caries-evidence for a dynamic disease process. J Dent Res 83, 39-42.

7. Mitrakul K, Asavanud Y, Vongsavan K (2012) Prevalence of five biofilm-related oral streptococci from plaques of Thai children. J Clin Pediatr Dent 36, 161-6.

8. Mitrakul K, Vongsavan K, Suratanachaikul P (2013) Prevalence of Streptococcus mutans and Lactobacillus fermentum and their association with caries and dietary habits in preschool Thai children. Eur Arch Paediatr Dent 14, 83-7.

9. Kanasi E, Dewhirst FE, Chalmers NI, Kent R Jr, Moore A, Hughes CV, et al (2012) Clonal analysis of the microbiota of severe early childhood caries. Caries Res 44, 485-97.

10. Berkowitz RJ (2006) Mutans streptococci: Acquisition and transmission. Pediatr Dent 28, 106-9.

11. Hata S, Hata H, Miyasawa-Hori H, Kudo A, Mayanagi H (2006) Quantitative detection of Streptococcus mutans in the dental plaque of Japanese preschool children by real-time PCR. Lett Appl Microbiol 42, 127-31.

12. Napimoga MH, Kamiya RU, Rosa RT, Rosa EAR, Höfling JF, Mattos-Graner RO, Gonçalves RB (2004) Genotypic diversity and virulence traits of Streptococcus mutans in caries-free and caries-active individuals. $J$ Med Microbiol 53, 697-703.

13. Hanada N, Kuramitsu HK (1988) Isolation and characterization of the Streptococcus mutans gtfC gene, coding for synthesis of both soluble and insoluble glucans. Infect Immun 56, 1999-2005.

14. Solórzano-Santos F, Miranda-Novales MG (2012) Essential oils from aromatic herbs as antimicrobial agents. Curr Opin Biotechnol 23, 136-41.

15. Galvão LCC, Furletti VF, Bersan SMF, da Cunha MG, Ruiz ALTG, de Carvalho JE, et al (2012) Antimicrobial activity of essential oils against Streptococcus mutans and their antiproliferative effects. Evid Based Complement Altern Med 2012, 751435.

16. Srisukh V, Tribuddharat C, Nukoolkarn V, Bunyapraphatsarac N, Chokephaibulkitd K, Phoomniyomb S, et al (2012) Antibacterial activity of essential oils from Citrus hystrix (makrut lime) against respiratory tract pathogens. Sci Asia 38, 212-7.

17. Mitrakul K, Srisatjaluk RL, Srisukh V, Vongsawan K (2015) Efficacy of Citrus hystrix sprays in decontaminating Streptococcus mutans on children's toothbrushes. Sci Asia 41, 28-34.

18. Tomás I, Henderson B, Diz P, Donos N (2010) In vivo oral biofilm analysis by confocal laser scanning microscopy: methodological approaches. In: MéndezVilas A, Díaz J (eds) Microscopy: Science, Technology, Applications and Education, Formatex Research Center, Badajoz, Spain, pp 597-606.
19. Handley PS, Sutton NA, Hughes N (1993) Problems associated with electron microscopy of biofilms. In: Wimpenny JWT (ed) Bacterial Biofilms and Their Control in Medicine and Industry, BioLine, Cardiff, UK, pp 61-6.

20. Dige I, Nilsson H, Kilian M, Nyvad B (2007) In situ identification of streptococci and other bacteria in initial dental biofilm by confocal laser scanning microscopy and fluorescence in situ hybridization. Eur J Oral Sci 115, 459-67.

21. Ismail AI, Sohn W (1999) A systematic review of clinical diagnostic criteria of early childhood caries. J Publ Health Dent 59, 171-91.

22. Kuvatanasuchati J (1999) Dentocult SM-Strip mutans kit. Chula Univ Dent $J$ 22, 17-22, [in Thai].

23. Konishi N, Torii Y, Kurosaki A, Takatsuka T, Itota T, Yoshiyama M (2003) Confocal laser scanning microscopic analysis of early plaque formed on resin composite and human enamel. J Oral Rehabil 30, 790-5.

24. Welin-Neilands J, Svensäter G (2007) Acid tolerance of biofilm cells of Streptococcus mutans. Appl Environ Microbiol 73, 5633-8.

25. Koo H, Hayacibara MF, Schobel BD, Cury JA, Rosalen PL, Park YK, et al (2003) Inhibition of Streptococcus mutans biofilm accumulation and polysaccharide production by apigenin and $t t$-farnesol. $J$ Antimicrob Chemother 52, 782-9.

26. Nuryastuti T, van der Mei HC, Busscher HJ, Iravati S, Aman AT, Krom BP (2009) Effect of cinnamon oil on icaA expression and biofilm formation by Staphylococcus epidermidis. Appl Environ Microbiol 75, 6850-5. 